\title{
Progress on BIG 1-02/IBCSG 27-02/NSABP B-37, a Prospective Randomized Trial Evaluating Chemotherapy after Local Therapy for Isolated Locoregional Recurrences of Breast Cancer
}

\author{
Irene L. Wapnir, MD, ${ }^{1,2}$ Stefan Aebi, MD ${ }^{3}$ Shari Gelber, MS, ${ }^{4,5}$ Stewart J. Anderson, \\ $\mathrm{PhD},{ }^{1,6}$ István Láng, MD, ${ }^{7}$ André Robidoux, MD ${ }^{8}$ Eleftherios P. Mamounas, MD, MPH, ${ }^{1,9}$ \\ and Norman Wolmark, MD ${ }^{1,10}$
}

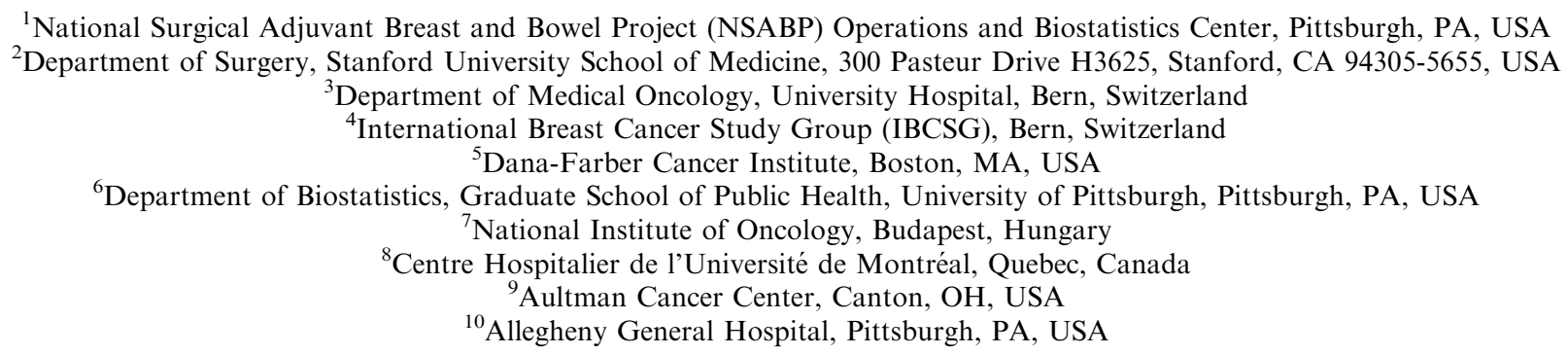

Background: The utility of chemotherapy for women who experience a locoregional recurrence after primary treatment of early breast cancer remains an open question. An international collaborative trial is being conducted by the Breast International Group (BIG), the International Breast Cancer Study Group (IBCSG), and the National Surgical Adjuvant Breast and Bowel Project (NSABP) to determine the effectiveness of cytotoxic therapy for these patients, either alone or in addition to selective use of hormonal therapy and trastuzumab.

Methods: The trial population includes women who have had a previous diagnosis of invasive breast cancer treated by mastectomy or breast-conserving surgery, but subsequently develop an isolated local and/or regional ipsilateral invasive recurrence. Excision of all macroscopic tumor without evidence of systemic disease is required for study entry. Patients are randomized to receive chemotherapy or no chemotherapy; type of chemotherapy is not protocol-specified. Radiation, hormonal therapy, and trastuzumab are given as appropriate. The primary endpoint is disease-free survival (DFS). Quality-of-life measurements are collected at baseline, and then at 9 and 12 months. The accrual goal is 977 patients.

Results: This report describes the characteristics of the first 99 patients. Sites of recurrence at study entry were: breast $(56 \%)$, mastectomy scar/chest wall $(35 \%)$, and regional lymph nodes $(9 \%)$. Two-thirds of patients have estrogen-receptor-positive recurrences.

Conclusion: This is the only trial actively investigating the question of "adjuvant" chemotherapy in locally recurrent breast cancer. The case mix of accrual to date indicates a broad representation of this patient population.

Published online September 11, 2008.

Address correspondence and reprint requests to: Irene L. Wapnir, MD; E-mail: wapnir@stanford.edu

Published by Springer Science+Business Media, LLC @ 2008 The Society of Surgical Oncology, Inc.
The risk of developing metastatic disease is increased among women who develop isolated locore- 
gional recurrences following treatment of primary breast cancer. ${ }^{1}$ Stage of the index cancer, use of prior adjuvant therapy, and time to recurrence may modulate the prognosis of this patient population. ${ }^{2-9}$ Published series report less than 50\% 5-year survival in patients experiencing post-mastectomy recurrences and $39-84 \%$-year survival in women experiencing ipsilateral breast tumor recurrences after breast-conserving therapy..$^{2-6,9-19}$ In a cross-protocol analysis of five National Surgical Adjuvant Breast and Bowel Project (NSABP) node-positive prospective randomized trials, 5-year disease-free survival (DFS) and overall survival (OS) following ipsilateral breast tumor recurrence (IBTR) were $51.4 \%$ and $59.9 \%$, respectively. ${ }^{9}$ In contrast, patients with other locoregional recurrences (oLRR), excluding IBTRs, fared considerably worse, with 5 -year survival of $24.1 \%$.

Three small prospective randomized clinical trials have attempted to test the effectiveness of systemic therapy in patients with locally recurrent breast cancer. $^{20-22}$ The Swiss Group for Clinical Cancer Research (SAKK) trial was able to randomize only 50 women with such high-risk tumors to observation versus vincristine, doxorubicin, and cyclophosphamide and closed the study due to the poor accrual with no results reported to date. ${ }^{23}$ In the same SAKK trial patients with lower-risk estrogen-receptor-positive $(\mathrm{ER}+)$ tumors showed improvement in 5-year DFS if randomized to tamoxifen after radical excision of post-mastectomy recurrences and local radiotherapy of $50 \mathrm{~Gy} .{ }^{10}$

An ongoing international multicenter clinical trial (BIG 1-02/IBCSG 27-02/NSABP B-37) is attempting to determine if the substantial risk of systemic relapse following a locoregional recurrence can be reduced by the administration of chemotherapy either alone or in addition to appropriate targeted systemic therapies such as hormonal therapy and trastuzumab. The routine use of alkylating agents, anthracyclines, and/or taxanes as prior adjuvant therapy as well as selective estrogen-receptor modulators and aromatase inhibitors mandates flexibility in the selection of systemic therapies for isolated locoregional relapse. Although it would have been conceptually preferable to restrict possible treatments to a few specific regimens, such a design was impractical given the variety of first-line adjuvant treatments used internationally for adjuvant therapy of breast cancer.

Our intent herein is to describe progress on this clinical trial, to encourage participation, and to increase awareness among surgical oncologists who routinely care for such patients.

\section{METHODS}

\section{Study Design and Patient Entry}

The trial (BIG 1-02/IBCSG 27-02/NSABP B-37) opened with the Breast International Group (BIG) and International Breast Cancer Study Group (IBCSG) in 2002, and became a collaborative effort with the NSABP in 2005. About half of the patients entered thus far have come from North American centers. This study was approved by the appropriate institutional review committees in accordance with assurances filed with and approved by the Department of Health and Human Services. Written informed consent was required for participation in each trial.

Figure 1 depicts the trial schema. Randomization to either observation (with or without radiation) or chemotherapy (with or without radiation) must take place within 12 weeks of definitive surgical resection of the locoregional recurrence. Patients are stratified according to the use of prior chemotherapy, receptor status [ER- and/or progesterone receptor (PgR)-positive or both negative, as determined by institutional guidelines] of the recurrence, and the location of the recurrence (breast, mastectomy scar/chest wall, or regional lymph nodes).

The trial is open to patients who have developed a histologically proven isolated invasive locoregional recurrence following the treatment of a primary invasive breast cancer. ${ }^{24}$ Patients can be enrolled by members of the appropriate groups by accessing the websites of those groups: IBCSG at http://www.ibcsg.org/public/ general_pages/trial/open/trial_27-02.shtml; NSABP at http://www.nsabp.pitt.edu/B-37.asp; BIG at http:// www.ibcsg27-02_big1-02@ibcsg.org; and by nonmembers through the Clinical Trials Support Unit (CTSU) at http://www.ctsu.org. Patients must have received either breast-conserving therapy or mastectomy for the index cancer and must have had all macroscopic recurrent disease excised. Specifically, margins must be either uninvolved (R0) or only microscopically involved (R1) to meet study selection criteria. Mastectomy or repeat lumpectomy is allowed for patients who received prior lumpectomy.

Only women with histologically proven first local and/or regional recurrence of invasive breast cancer on the same side as their primary cancer are considered eligible. Patients may enter the study irrespective of whether lymph node staging surgery or radiation therapy was used in the treatment of the primary breast cancer. Sites of recurrence are defined as: any soft tissue of the ipsilateral conserved breast or the chest wall, mastectomy scar, and/or skin. Regional 


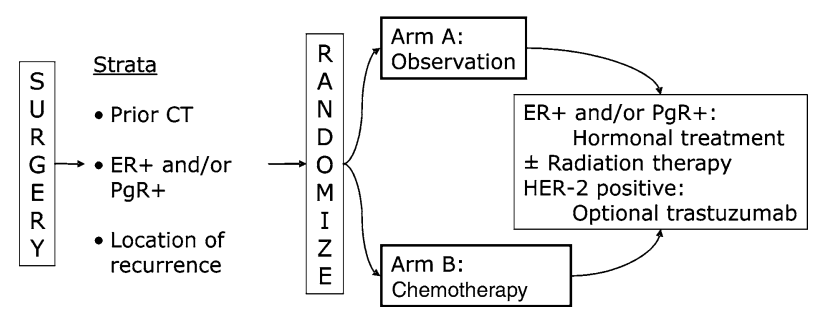

FIG. 1. Schema for the BIG 1-02/IBCSG 27-02/NSABP B-37 study. This figure was previously published in a modified form. ${ }^{24}$

failure is defined as a tumor recurrence in the ipsilateral axillary lymph nodes, extranodal soft tissue of the ipsilateral axilla, and/or ipsilateral internal mammary nodes. Patients with supraclavicular lymph node recurrences, recurrences in the opposite breast, or any evidence of distant disease are not eligible.

Prior to study entry, written informed consent, baseline quality-of-life assessment, and stratification factor information are required. Pathology reports of the primary tumor and recurrence are required. NonNorth-American institutions are encouraged to store tumor blocks from both the primary and recurrent tumors for future pathology studies.

\section{Treatment for Locoregional Recurrence}

Chemotherapy, if assigned, should begin within 4 weeks of the date of randomization. The choice of chemotherapy drugs, dose adjustments, and use of supportive therapy is left to the discretion of the investigator, but multidrug chemotherapy regimens for at least three cycles or 3 to 6 months are suggested. Estrogen receptor downregulators, aromatase inhibitors, and ovarian suppression are all acceptable alternatives for the required hormonal therapy for estrogen receptor positive $(\mathrm{ER}+)$ and/or progesterone positive $(\mathrm{PR}+)$ tumors. Adjuvant trastuzumab therapy is allowed for HER-2 overexpressing tumors but can only be administered with chemotherapy if randomized to the chemotherapy arm. Intent to use trastuzumab therapy must be declared prior to randomization.

When radiotherapy is indicated, a dose equivalent to $\geq 40$ Gy is required. Radiotherapy can be administered before, during or after chemotherapy. Patients who develop an IBTR and are treated with mastectomy are not required to undergo radiation therapy even if radiotherapy was not a component of the original breast-conserving therapy. Radiation therapy equivalent to $\geq 40 \mathrm{~Gy}$ is mandatory for all other patients who have not received radiation. For those previously irradiated patients, additional radiation is considered unnecessary if margins of resection are negative (R0). Additional radiation, such as a smallvolume boost to the high-risk area is required if margins are microscopically positive. In the latter case, the radiation field must encompass a safety margin beyond the positive margin.

\section{Quality-of-Life Study}

The quality-of-life study includes a baseline assessment (before randomization) and assessments at 9 and 12 months after randomization to allow treatment comparisons after chemotherapy is completed. Each assessment includes global linear analog self-assessment (LASA) indicators for physical wellbeing, mood, coping (PACIS), perceived social support, and subjective health estimation (SHE) ${ }^{25}$ LASA indicators specific to symptoms of nausea and vomiting, tiredness, hot flushes, and restrictions in arm movement are also included.

\section{Data Analyses}

The primary analysis will be intent-to-treat and the calculated study sample size is 977 patients. Based on previous studies we assume that the overall 5-year DFS for the group receiving no chemotherapy will be $50 \%$. A total of 347 events is required to detect an improvement in 5-year DFS to $60 \%$ (hazard ratio 0.74 ) with $80 \%$ power using a two-sided 0.05 level log-rank test. This accounts for two interim analyses during the conduct of the study. To account for nonevaluable cases (5\%), the target accrual should be 977 total patients. The outcome measures for efficacy comparisons are DFS, systemic DFS, and OS.

\section{RESULTS}

The current report summarizes the clinical-pathological characteristics of the first 99 patients randomized onto BIG 1-02/IBCSG 27-02/NSABP B-37. At study entry most patients had a local recurrence, prior chemotherapy, were postmenopausal, and had hormone-receptor-positive disease (Table 1). The recurrences occurred in the ipsilateral breast in 56\%, the mastectomy skin/chest wall in $35 \%$, and in regional lymph nodes in 9\% (Fig. 2). Sixty-five percent of patients had received adjuvant chemotherapy. Recurrent tumors were hormone receptor positive by institutional standards in $65 \%$ of patients. Table 1 
TABLE 1. Incidence of patient and disease characteristics at study entry

\begin{tabular}{|c|c|c|c|}
\hline & Observation & Chemotherapy & Total \\
\hline Total patients & 50 & 49 & 99 \\
\hline \multicolumn{4}{|l|}{ ER/PgR status } \\
\hline Negative & $18(36 \%)$ & $17(35 \%)$ & $35(35 \%)$ \\
\hline Positive & $32(64 \%)$ & $32(65 \%)$ & $64(65 \%)$ \\
\hline \multicolumn{4}{|l|}{ Prior chemotherapy } \\
\hline No & $18(36 \%)$ & $17(35 \%)$ & $35(35 \%)$ \\
\hline Yes & $32(64 \%)$ & $32(65 \%)$ & $65(65 \%)$ \\
\hline \multicolumn{4}{|c|}{ Location of primary recurrence } \\
\hline Breast & $27(54 \%)$ & $28(57 \%)$ & $55(56 \%)$ \\
\hline Mx scar/chest wall & $18(36 \%)$ & $17(35 \%)$ & $35(35 \%)$ \\
\hline Regional lymph nodes & $5(10 \%)$ & $4(8 \%)$ & $9(9 \%)$ \\
\hline \multicolumn{4}{|l|}{ Menopausal status } \\
\hline Pre & $11(26 \%)$ & $10(27 \%)$ & $21(26 \%)$ \\
\hline Post & $32(74 \%)$ & $27(73 \%)$ & $59(74 \%)$ \\
\hline Not yet available & 7 & 12 & 19 \\
\hline \multicolumn{4}{|l|}{ Tumor size } \\
\hline$\leq 2 \mathrm{~cm}$ & $27(69 \%)$ & $24(67 \%)$ & $51(68 \%)$ \\
\hline$>2 \mathrm{~cm}$ & $12(31 \%)$ & $12(33 \%)$ & $24(32 \%)$ \\
\hline Not yet available & 11 & 13 & 24 \\
\hline \multicolumn{4}{|l|}{ Age } \\
\hline $30-39$ years & $5(10 \%)$ & $3(6 \%)$ & $8(8 \%)$ \\
\hline $40-49$ years & $10(20 \%)$ & $11(22 \%)$ & $21(21 \%)$ \\
\hline $50-59$ years & $19(38 \%)$ & $22(45 \%)$ & $41(41 \%)$ \\
\hline 60-69 years & $10(20 \%)$ & $12(24 \%)$ & $22(22 \%)$ \\
\hline$\geq 70$ years & $6(12 \%)$ & $1(2 \%)$ & $7(7 \%)$ \\
\hline
\end{tabular}

ER, estrogen receptor; $\mathrm{PgR}$, progesterone receptor.

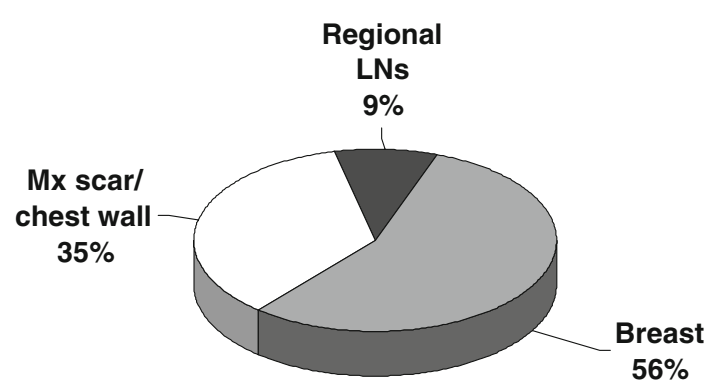

FIG. 2. Sites of locoregional recurrences in the first 99 patients.

shows that the patient and tumor characteristics were balanced according to randomized treatment group.

\section{DISCUSSION}

This study represents the last opportunity to formally assess whether chemotherapy adds any benefit to definitive local therapy and systemic targeted therapies for resected, isolated locoregional recurrence of breast cancer. Accrual to this trial has been slower than needed to complete the trial. We recognize that, since isolated locoregional recurrences are infrequent, institutions may have relatively few eligible patients, which can serve as a potential deterrent to activation of the study.
Additionally, in the absence of randomized clinical trial data, patients and physicians have developed biases for or against chemotherapy, which can be a substantial barrier to the successful conduct of scientifically valid trials. Because nearly half the patients entered have chest wall or regional nodal recurrences and over one-third have ER-negative tumors, it is likely that both high- and low-risk cases are being accrued, and thus the trial population is representative of the population at large. BIG 1-02/NSABP B-37/IBCSG 27-02 is an important final effort aimed at providing definitive data needed to evolve evidence-based therapeutic guidelines for patients with isolated invasive recurrences of breast cancer. The trial can only be completed if surgical and medical oncologists commit to the importance of answering the question being addressed and insist the study be opened and supported in their institution even though accrual will be challenging.

\section{ACKNOWLEDGEMENTS}

The authors would like to thank the participating centers, including the Dutch Breast Cancer Trialists' Group (BOOG), the Spanish Breast Cancer Research Group (GEICAM), the International Breast Cancer Study Group (IBCSG), and the National Surgical Adjuvant Breast and Bowel Project (NSABP). The authors would also like to thank Karen Price, 
Director of Scientific Administration for the International Breast Cancer Study Group (IBCSG). Supported in part by Public Health Service Grants U10CA-12027, U10CA-69974, U10CA-37377, and U10CA-69651 from the National Cancer Institute, Department of Health and Human Services. The International Breast Cancer Study Group is supported in part by the Swiss Group for Clinical Cancer Research (SAKK), the Frontier Science and Technology Research Foundation, the Cancer Council Australia, the Australian New Zealand Breast Cancer Trials Group, the National Cancer Institute (CA75362), the Swedish Cancer Society, Cancer Research Switzerland/Oncosuisse, the Cancer Association of South Africa, and the Foundation for Clinical Research of Eastern Switzerland (OSKK).

\section{REFERENCES}

1. Early Breast Cancer Trialists' Collaborative Group. Favourable and unfavourable effects on long-term survival of radiotherapy for early breast cancer: an overview of the randomised trials. Lancet 2000; 355:1757-70.

2. Brunner $\mathrm{KW}$, Harder $\mathrm{F}$, Greiner R, et al. [Loco-regional recurrence following surgery of breast carcinoma: prognostic factors and therapeutic consequences]. Schweiz Med Wochenschr 1988;118:1976-81. [Article in German].

3. Schwaibold F, Fowble BL, Solin LJ, et al. The results of radiation therapy for isolated local regional recurrence after mastectomy. Int J Radiat Oncol Biol Phys 1991; 21:299-310.

4. Halverson KJ, Perez CA, Kuske RR, et al. Survival following locoregional recurrence of breast cancer: univariate and multivariate analysis. Int J Radiat Oncol Biol Phys 1992; 23:28591.

5. Willner J, Kiricuta IC, Kolbl O. Locoregional recurrence of breast cancer following mastectomy: always a fatal event? Results of univariate and multivariate analysis. Int $J$ Radiat Oncol Biol Phys 1997; 37:853-63.

6. Kamby C, Sengelov L. Pattern of dissemination and survival following isolated locoregional recurrence of breast cancer. A prospective study with more than 10 years of follow up. Breast Cancer Res Treat 1997; 45:181-92.

7. Wallgren A, Bonett M, Gelber R, et al. Risk factors for locoregional recurrence among breast cancer patients: results from International Breast Cancer Study Group Trials I through VII. J Clin Oncol 2003; 21:1205-13.

8. Voogd AC, van Oost FJ, Rutgers EJ, et al. Long-term prognosis of patients with local recurrence after conservative surgery and radiotherapy for early breast cancer. Eur J Cancer 2005; 41:2637-44.

9. Wapnir IL, Anderson SJ, Mamounas EP, et al. Prognosis after ipsilateral breast tumor recurrence and locoregional recurrences in five National Surgical Adjuvant Breast and Bowel
Project node-positive adjuvant breast cancer trials. $\mathrm{J}$ Clin $\mathrm{On}$ col 2006; 24:2028-37.

10. Waeber M, Castiglione-Gertsch M, Dietrich D, et al. Adjuvant therapy after excision and radiation of isolated postmastectomy locoregional breast cancer recurrence: definitive results of a phase III randomized trial (SAKK 23/82) comparing tamoxifen with observation. Ann Oncol 2003; 14:1215-21.

11. Stotter A, Atkinson EN, Fairston BA, et al. Survival following locoregional recurrence after breast conservation therapy for cancer. Ann Surg 1990; 212:166-72.

12. Fowble B, Solin LJ, Schultz DJ, et al. Breast recurrence following conservative surgery and radiation: patterns of failure, prognosis, and pathologic findings from mastectomy specimens with implications for treatment. Int J Radiat Oncol Biol Phys $1990 ; 19: 833-42$.

13. Haffty BG, Fischer D, Beinfield M, et al. Prognosis following local recurrence in the conservatively treated breast cancer patient. Int J Radiat Oncol Biol Phys 1991; 21:293-8.

14. Abner AL, Recht A, Eberlein T, et al. Prognosis following salvage mastectomy for recurrence in the breast after conservative surgery and radiation therapy for early-stage breast cancer. J Clin Oncol 1993; 11:44-8.

15. Cajucom CC, Tsangaris TN, Nemoto T, et al. Results of salvage mastectomy for local recurrence after breast-conserving surgery without radiation therapy. Cancer 1993; 71:1774-9.

16. Leborgne F, Leborgne JH, Ortega B, et al. Breast conservation treatment of early stage breast cancer: patterns of failure. Int $J$ Radiat Oncol Biol Phys 1995; 31:765-75.

17. Haffty BG, Reiss M, Beinfield M, et al. Ipsilateral breast tumor recurrence as a predictor of distant disease: implications for systemic therapy at the time of local relapse. J Clin Oncol 1996; 14:52-7.

18. Dalberg K, Mattsson A, Sandelin K, et al. Outcome of treatment for ipsilateral breast tumor recurrence in early-stage breast cancer. Breast Cancer Res Treat 1998; 49:69-78.

19. Doyle T, Schultz DJ, Peters C, et al. Long-term results of local recurrence after breast conservation treatment for invasive breast cancer. Int J Radiat Oncol Biol Phys 2001; 51:74-80.

20. Borner M, Bacchi M, Goldhirsch A, et al. First isolated locoregional recurrence following mastectomy for breast cancer: results of a phase III multicenter study comparing systemic treatment with observation after excision and radiation. Swiss Group for Clinical Cancer Research. J Clin Oncol 1994; 12:2071-7.

21. Fentiman IS, Balkwill FR, Cuzick J, et al. A trial of human alpha interferon as an adjuvant agent in breast cancer after loco-regional recurrence. Eur J Surg Oncol 1987; 13:425-8.

22. Olson CE, Ansfield FJ, Richards MJ, et al. Review of local soft tissue recurrence of breast cancer irradiated with and without actinomycin-D. Cancer 1977; 39:1981-3.

23. Rauschecker H, Clarke M, Gatzemeier W, et al. Systemic therapy for treating locoregional recurrence in women with breast cancer. Cochrane Database Syst Rev 2007; CD002195.

24. Wapnir I, Aebi S, Geyer CE, et al. A randomized clinical trial of adjuvant chemotherapy for radically resected locoregional relapse of breast cancer: IBCSG 27-02, BIG 1-02, NSABP B37. Clin Breast Cancer 2008; 8:287-92.

25. Hurny C, van Wegberg B, Bacchi M, et al. Subjective health estimations (SHE) in patients with advanced breast cancer: an adapted utility concept for clinical trials. Br J Cancer 1998; 77:985-91. 